\title{
Temperature-Sensitive Gels for Intratumoral Delivery of $\beta$-Lapachone: Effect of Cyclodextrins and Ethanol
}

\author{
Marcilio S. S. Cunha-Filho, ${ }^{1}$ Carmen Alvarez-Lorenzo, ${ }^{2}$ \\ Ramón Martínez-Pacheco, ${ }^{2}$ and Mariana Landinn ${ }^{2}$ \\ ${ }^{1}$ Faculdade de Ciências da Saúde, Universidade de Brasília (UnB), Campus Universitário Darcy Ribeiro, 70910-900 \\ Brasília-DF, Brazil \\ ${ }^{2}$ Departamento de Farmacia y Tecnología Farmacéutica, Facultad de Farmacia, Campus Vida, Universidad de Santiago, \\ 15782 Santiago de Compostela, Spain
}

Correspondence should be addressed to Mariana Landin, m.landin@usc.es

Received 20 October 2011; Accepted 15 January 2012

Academic Editors: D. Quintanar-Guerrero and A. Savaser

Copyright (C) 2012 Marcilio S. S. Cunha-Filho et al. This is an open access article distributed under the Creative Commons Attribution License, which permits unrestricted use, distribution, and reproduction in any medium, provided the original work is properly cited.

This work evaluated the potential of Pluronics (varieties F127 and P123) in combination with solubilizing agents to be used as syringeable in situ gelling depots of intratumoral $\beta$-lapachone $(\beta \mathrm{LAP})$. Pluronic dispersions prepared at various concentrations in the absence and the presence of ethanol and randomly methylated $\beta$-cyclodextrin $(\mathrm{RM} \beta \mathrm{CD})$ were characterized regarding their rheological properties, drug solubilization capacity, and in vitro release. Pluronic F127 (18-23\%) formulations combined high ability to solubilize $\beta$ LAP (enhancement solubility factor up to 50 ), adequate gel temperature range (over $25^{\circ} \mathrm{C}$ ), and gel strength at $37^{\circ} \mathrm{C}$ enough to guarantee the permanence of the formulation in the administration site for a period of time. $\beta$ LAP release rate was finely tuned by the concentration of the polymer and the addition of RM $\beta C D$ (diffusion coefficient ranging between 9 and $69 \mu \mathrm{g} \cdot \mathrm{cm}^{-2}$ ). The ethanol increases $\beta$ LAP release rate but simultaneously led to weak gels. This paper shows that $\beta$ LAP formulations involving temperature-reversible Pluronic gels may be suitable for intratumoral drug delivery purposes.

\section{Introduction}

Conventional systemic cancer chemotherapy has limited effectiveness in the treatment of solid tumours, the preferred therapy being surgical removal despite frequent recurrence. The use of local controlled release formulations of anticancer drugs is attracting much attention due to the unique physiology of solid tumours, which comprises a highly disordered vasculature and zones of rapidly proliferation cells where a formulation can be retained $[1,2]$.

$\beta$-lapachone ( $\beta \mathrm{LAP})$ is an anticancer drug that acts by a novel mechanism of direct activation checkpoint regulators inducing apoptosis, particularly useful for neoplasm of slow cell cycle like prostate, pancreatic, colon, and some ovarian and breast cancer [3-6]. Despite its great potential, several factors hinder its use, mainly its low aqueous solubility $[7,8]$ and its nonspecific distribution which leads to a low tumour concentration and/or a systemic toxicity [9]. An alternative approach for $\beta \mathrm{LAP}$ administration could be an injectable formulation containing appropriate polymers able to undergo a transition to semisolid depot into the tumour tissues $[1,10,11]$.

Pluronic (poloxamer or Lutrol) amphiphilic triblock copolymers of ethylene oxide (EO) and propylene oxide (PO) blocks (EOx-POy-EOx) self-aggregate as polymeric micelles possessing a relatively hydrophobic core in which poorly soluble drugs can be hosted. The incorporation of the drug into the micelles can improve drug solubility and chemical stability and also regulate the biodistribution and the cell accumulation [12, 13]. Therefore, Pluronic micelles have been shown particularly suitable for the development of formulations of anticancer agents [14] and thus they could be also useful for the photosensitive $\beta$ LAP [15]. Pluronic micellar solutions undergo a sol-to-gel transition when 
heating above a certain temperature due to a progressive dehydration of PPO and PEO blocks [12]. If the concentration is adequately chosen, the micellar entanglements at body temperature render a 3D physical network that behave as a viscoelastic depot able to sustain drug release at the site of application $[10,16]$. Furthermore, pluronics can alter the mechanisms responsible for multidrug-resistance in cancer cells $[17,18]$. Both micellization and gelling are reversible phenomena and can be affected by the presence of drugs or cosolvents in the formulation [19]. Nevertheless the findings are sometimes contradictory and, for example, quite opposite results have been reported regarding the effect of ethanol on the critical gel temperature and concentration of Pluronic F127 [20, 21]. The discrepancies could be related to the different technique used to determine the gel point or to the inherent polydispersion of the block copolymers and the presence of some impurities.

The aim of the study was to evaluate the potential of two Pluronic varieties, F127 and P123, to be used in the formulation of temperature-sensitive vehicles of $\beta$ LAP. For an efficient intratumoral delivery of $\beta \mathrm{LAP}$, the following essential criteria should be taken into account: (i) an adequate amount of $\beta$ LAP has to be solubilised; (ii) the formulation should be syringeable in the tumour; (iii) it should form a gel of sufficient consistency to guarantee the formation of a depot system; (iv) the depot should sustain drug release. To carry out the work, aqueous dispersions of the Pluronics at different concentrations were prepared and the effect of additives, such as randomly methylated $\beta$-cyclodextrin (RM $\beta \mathrm{CD}$ ) and ethanol, on $\beta \mathrm{LAP}$ solubility and gel properties was evaluated. Both $\mathrm{RM} \beta \mathrm{CD}$ [8] and ethanol could be an aid for drug solubilisation when micelles become saturated. However, both additives could alter the hydrophobic interactions among PPO blocks and thus decrease the solubilisation ability of the micelles [22]. A compromise between both effects should be reached. Additionally, the effect of sterilization by autoclaving on the rheological behaviour and physical stability of the systems was also studied.

\section{Materials and Methods}

2.1. Materials. $\beta$-lapachone ( $\beta$ LAP; batch L503; 3,4-dihydro-2,2-dimethyl-2H-naphthol-[1,2-b] pyran-5,6-dione; $\mathrm{C}_{15} \mathrm{H}_{14} \mathrm{O}_{3}$; MW 242.3) was supplied by Laboratorio Farmacêutico do Estado de Pernambuco, LAFEPE (Recife, Brazil) with purity estimated by DSC and HPLC in 99.9\%. Randomly methylated $\beta$-cyclodextrin ( $\mathrm{RM} \beta \mathrm{CD}$; degree of substitution 0.57) was kindly donated by Roquette (Barcelona, Spain). Pluronic F127 was purchased from Sigma-Aldrich (St. Louis, USA) and Pluronic P123 was supplied by BASF (Ludwigshafen, Germany). All other chemicals were of analytical grade. Purified water (Millipore, Milli Q Plus, Billerica, USA) was used.

2.2. Preparation of Pluronic Dispersions. Stock solutions of Pluronic F127 and P123 were prepared adding the adequate amount of copolymer to water under stirring and kept at $4^{\circ} \mathrm{C}$ until obtaining a clear transparent solution of 35\% (w/w) [12]. Then dilutions of Pluronic F127 $(18,23$, or $28 \% \mathrm{w} / \mathrm{w})$ and P123 $(28 \% \mathrm{w} / \mathrm{w})$ were prepared. When was needed, the drug and the $\mathrm{RM} \beta \mathrm{CD}$ or ethanol were incorporated in the solution used to dilute the concentrated Pluronic dispersions. Drug concentration tested was $0.2 \mathrm{mg} \cdot \mathrm{mL}^{-1}$ and additives concentrations were $5 \%(\mathrm{w} / \mathrm{v})$ for $\mathrm{RM} \beta \mathrm{CD}$ and $20 \%(\mathrm{v} / \mathrm{v})$ for ethanol.

2.3. Analytical Methods. $\beta$ LAP was determined spectrophotometrically at $257 \mathrm{~nm}$ (Agilent 8453, Germany). Calibration curve in water/ethanol $(1: 1 \mathrm{v} / \mathrm{v})$ was made using standard solutions in the range of 2 to $10 \mu \mathrm{g} \cdot \mathrm{mL}^{-1}$. No effect of additives on the spectrum of $\beta \mathrm{LAP}$ solution was observed.

2.4. Rheological Evaluation. The influence of temperature from $5^{\circ} \mathrm{C}$ to $40^{\circ} \mathrm{C}$ on the loss or viscous $\left(\mathrm{G}^{\prime \prime}\right)$ and storage or elastic $\left(\mathrm{G}^{\prime}\right)$ moduli of the dispersions was evaluated in a Rheolyst AR-1000 N rheometer (TA Instruments, Newcastle, UK) equipped with an AR2500 data analyzer, a Peltier plate, and a cone with a diameter of $60 \mathrm{~mm}$ and 1.58 degree. The gap was fitted to $50 \mu \mathrm{m}$. Measurements were performed at $0.5 \mathrm{rad} \cdot \mathrm{s}^{-1}$ with an oscillatory stress of $0.1 \mathrm{~Pa}$ and a ramp of $2^{\circ} \mathrm{C} \cdot \mathrm{min}^{-1}$. The temperature at which the elastic modulus cross-overs the viscous modulus was considered the gel temperature [19].

Creep-recovery assays were performed at $37^{\circ} \mathrm{C}$. During the creep phase, a fixed shear stress of $10 \mathrm{~Pa}$ for Pluronic F127 systems and $0.3 \mathrm{~Pa}$ for Pluronic P123 systems was applied for $5 \mathrm{~min}$. The samples were equilibrated at $37^{\circ} \mathrm{C}$ during $2 \mathrm{~h}$ before assay. Gel strength was calculated as the inverse of the maximum value of compliance of the retardation phase of creep-recovery profiles. The experiments were carried out in triplicate.

2.5. $\beta$ LAP Solubilization. $\beta$ LAP solubility was evaluated by adding an excess of drug into $3 \mathrm{~mL}$ of blank Pluronic systems placed in glass ampoules. The suspensions were sonicated during $15 \mathrm{~min}$ and mechanically shaken (Gallenkamp, Loughborough UK) at $200 \mathrm{rpm}$ for 7 days at $4^{\circ} \mathrm{C}$. Then, the systems were filtered through $0.45 \mu \mathrm{m}$ nylon filters (Millipore Corp, Billerica, USA) and diluted with water/ethanol solution $(1: 1 \mathrm{v} / \mathrm{v})$ to determine spectrophotometrically $\beta$ LAP concentration. The experiments were carried out in quadruplicate. The enhancement factor (EF) was calculated as the ratio between the $\beta \mathrm{LAP}$ solubility value in the system and the $\beta$ LAP solubility in pure water $\left(0.03 \mathrm{mg} \cdot \mathrm{mL}^{-1}\right)[8]$.

2.6. In Vitro Release Assays. $\beta$ LAP diffusion rate from Pluronic dispersions was studied, in quadruplicate, using horizontal side-by-side diffusion cells (Crown glass Corp., Somerville, NJ), separated by a dialysis membrane of a molecular weight cut-off at 7000 Daltons (Visking corp., London, UK) and a diffusional area of $0.64 \mathrm{~cm}^{2}$. Pluronic dispersions $(2 \mathrm{~mL})$ containing $\beta \mathrm{LAP}$ at a concentration of $0.2 \mathrm{mg} \cdot \mathrm{mL}^{-1}$ were placed in the donor chamber at $37^{\circ} \mathrm{C}$. The receptor medium, phosphate buffer $\mathrm{pH} 6.8$ [23], was continuously stirred with magnetic bar. During $20 \mathrm{~h}$ samples 
TABle 1: Gel temperature of Pluronic F127 and P123 systems solely or containing 5\% (w/v) RM $\beta$ CD and 20\% (v/v) ethanol: mean values and, in parenthesis, the standard deviations.

\begin{tabular}{cccccc}
\hline & \multicolumn{1}{c}{ Pluronic $\%$} & Without drug or additives & $+\beta \mathrm{LAP}$ & $\begin{array}{l}+\beta \mathrm{LAP} \\
+ \text { ethanol }\end{array}$ & $\begin{array}{l}+\beta \mathrm{LAP} \\
+\mathrm{RM} \beta \mathrm{CD}\end{array}$ \\
\hline \multirow{3}{*}{$\mathrm{F} 127$} & $18 \%$ & $25.5^{\circ} \mathrm{C}(0.0)$ & $24.1^{\circ} \mathrm{C}(0.6)$ & $6.0^{\circ} \mathrm{C}(2.0)$ & $29.1^{\circ} \mathrm{C}(0.7)$ \\
& $23 \%$ & $19.0^{\circ} \mathrm{C}(0.0)$ & $18.9^{\circ} \mathrm{C}(0.6)$ & $11.2^{\circ} \mathrm{C}(0.7)$ & $23.7^{\circ} \mathrm{C}(0.6)$ \\
\hline $\mathrm{P} 123$ & $28 \%$ & $11.6^{\circ} \mathrm{C}(0.6)$ & $12.8^{\circ} \mathrm{C}(0.6)$ & - & $15.7^{\circ} \mathrm{C}(0.8)$ \\
\hline
\end{tabular}

were collected regularly and replaced with fresh buffer in order to keep sink conditions. The $\beta$ LAP concentration in the solutions was determined as previously described.

2.7. Autoclaving. Systems with $28 \%$ copolymer containing or not drug and additives were placed in glass ampoules and autoclaved for 20 minutes at $121^{\circ} \mathrm{C}$ (Raypa model AES1219, Terrasa, Spain). Samples were then stored at $4^{\circ} \mathrm{C}$ until characterization. Gel temperature and rheological behaviour after autoclaving were studied as described previously. Samples were observed under optical microscopy (Olympus SZ60 connected to a video camera Olympus DP12, Tokyo, Japan), and the $\beta$ LAP remaining in solution was determined spectrophotometrically.

2.8. Statistical Analysis. The statistical analyses of rheological measurements were performed by the one-way analysis of variance (ANOVA) followed by least significant difference test using Statgraphics plus version $(\alpha=0.05)$.

\section{Results and Discussion}

3.1. Rheological Properties. The concentration range of Pluronics to produce adequate systems for intratumoral administration was chosen on the basis of preliminary studies. Concentrations between 18-28\% for Pluronic F127 and 28\% for Pluronic P123 combine syringeability and in situ gelling. Below 18\% Pluronic F127 does not form gels at $37^{\circ} \mathrm{C}$, but above $28 \%$, gels are formed even below $10^{\circ} \mathrm{C}$ making their handling difficult. The concentration range for obtaining Pluronic P123 systems that undergo the sol-gel transition at body temperature is narrower. Concentrations lower than $28 \%$ form gels above $37^{\circ} \mathrm{C}$ and at a higher concentration the system becomes a gel even at $4^{\circ} \mathrm{C}$ being not syringeable. The gel temperatures of the systems studied are shown in Table 1. Results of Pluronic F127 systems are in agreement with data in the literature [16]. In the concentration range studied, a close linear correlation between polymer concentration and the gel temperature was observed:

Gel temperature $\left({ }^{\circ} \mathrm{C}\right)$

$$
=50.67-1.39 \cdot(\text { Pluronic F127 }(\%)) ; r^{2}=0.9986 .
$$

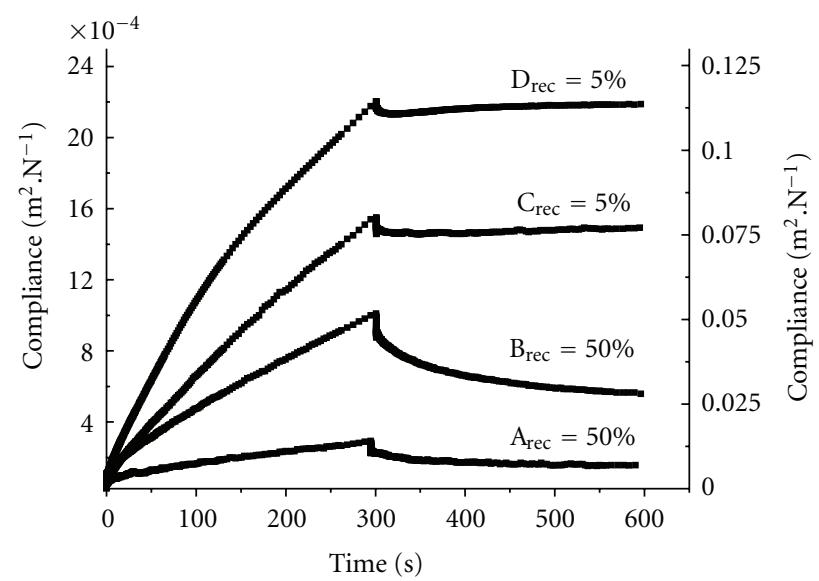

Figure 1: Creep-recovery profiles $\left(37^{\circ} \mathrm{C}\right)$ with indications of recovery percentages for the four characteristic rheological behaviour groups, namely, A (left axis): Pluronic F127 at 28\% and 23\% (without additive; drug; drug $+\mathrm{RM} \beta \mathrm{CD}$ ); B (left axis): Pluronic F127 at 18\% (without additive; drug; drug + RM $\beta \mathrm{CD}$ ); C (left axis): F127 at 23\% (drug + ethanol); and D (right axis): Pluronic P123 at $28 \%$ (without additive; drug; drug + ethanol; drug + RM $\beta C D$ ).

The addition of drugs and/or cosolvents can extensively modify the gel temperature of the Pluronic systems [19] with important repercussions on their utility for intratumoral administration. For the Pluronic systems studied, the incorporation of $\beta$ LAP did not cause significant changes $(\alpha<0.05)$ in the gel temperature. By contrast, the addition of ethanol (up to 20\%) dramatically decreased the gel temperature of 23\% Pluronic F127 and 28\% Pluronic P123 estimated as the temperature at which the elastic modulus cross-overs the viscous modulus (Table 1). However, the gels were softer (lower $\mathrm{G}^{\prime}$ and $\mathrm{G}^{\prime \prime}$ after the sol-to-gel transition) than those prepared without additives. Interestingly, the incorporation of ethanol caused 18\% Pluronic F127 system to remain as a low viscosity solution at temperatures beyond $37^{\circ} \mathrm{C}$, whilst 28\% Pluronic F127 gel was not liquefied even below at $4^{\circ} \mathrm{C}$. Thus, ethanol caused opposite effects depending on the copolymer concentration. The reasons behind these findings are not clear but should be related to that ethanol makes micellization more difficult, but when micelles are formed, ethanol incorporates into the micellar core causing elongation (worm-like micelles), as already demonstrated for the most hydrophobic variety tested Pluronic P123 
TABLE 2: Gel strength $\left(\mathrm{N} \cdot \mathrm{m}^{-2}\right)$ of the systems at $37^{\circ} \mathrm{C}$ : mean values and, in parenthesis, the standard deviations.

\begin{tabular}{cccccc}
\hline \multicolumn{2}{c}{ Pluronic $\%$} & Without drug or additives & $+\beta$ LAP & $\begin{array}{l}+\beta \text { LAP } \\
+ \text { ethanol }\end{array}$ & $\begin{array}{l}+\beta \text { LAP } \\
+ \text { RM } \beta \text { CD }\end{array}$ \\
\hline \multirow{2}{*}{ F127 } & $18 \%$ & $1554(542)$ & $1740(124)$ & - & $1382(462)$ \\
& $23 \%$ & $5740(1250)$ & $5698(2821)$ & $692(156)$ & $4827(1763)$ \\
\hline P123 & $28 \%$ & $6524(2300)$ & $5174(583)$ & - & $5892(850)$ \\
\hline
\end{tabular}

[24]. The increase in the micellar size may favour certain entanglement among PEO blocks of neighbour micelles, leading to the cross-over of $\mathrm{G}^{\prime}$ and $\mathrm{G}^{\prime \prime}$ at lower temperature. However, the transition from soft to hard gel requires that the micelles aggregate to reach a percolation threshold. As previously shown using SAXS, disorder in the micellar aggregates results in soft gels, while ordered packing in bcc or fcc structures results in hard gels [21]. Our results are in reasonable agreement with those of Jones et al. [20] and Chaibundit et al. [21] taking into account that the inverted-tube test identifies hard gel formation while the dynamic oscillatory analysis also enables the identification of soft gel formation. Therefore, the addition of ethanol may turn Pluronic dispersions into inappropriate formulations for intratumoral injection purposes.

The incorporation of $\mathrm{RM} \beta \mathrm{CD}$ at $5 \% \mathrm{w} / \mathrm{w}$ raised the gel temperature of all systems studied especially of Pluronic P123 dispersions, which is in agreement with results previously reported [25]. This fact can be explained by the formation of supramolecular assemblies named polypseudorotaxanes in which the PPO blocks are inserted in the cyclodextrin cavities [22]. As a consequence, the copolymer unimers involved in the supramolecular structure find that it is difficult to form micelles. Thus, the critical micellar and gelling concentrations of the copolymer increase.

To gain further insight into the rheological properties of the gels at $37^{\circ} \mathrm{C}$, creep-recovery profiles were recorded (Figure 1). The Pluronic dispersions studied can be classified into four groups of different rheological behaviours. Group A, the one with the highest viscosity, includes 23\% and $28 \%$ Pluronic F127 dispersions without additives or with $\beta$ LAP or $\beta$ LAP and RM $\beta$ CD. Group B corresponds to $18 \%$ Pluronic F127 formulated without additives or with $\beta$ LAP or $\beta \mathrm{LAP}$ and RM $\beta \mathrm{CD}$. Group $\mathrm{C}$ includes the $23 \% \mathrm{~F} 127$ formulations with the drug and ethanol. Group D (with the lowest viscosity) corresponds to $28 \%$ Pluronic P123 systems with or without additives.

The creep-recovery profiles exhibited an important elastic component for groups A and B (Figure 1) with a total recovery around $50 \%$, which means that these systems form a structured network able to store energy. By contrast, groups $\mathrm{C}$ and D presented a minor elastic recovery (5\%) and a predominant viscous behaviour, which is related to their softer structure. The parameter "gel strength" at $37^{\circ} \mathrm{C}$ was calculated as the inverse of compliance of the retardation phase of creep-recovery profiles (Table 2). The incorporation of ethanol led to a strong reduction on gel strength and also to a decrease in elasticity for Pluronic F127 dispersions. This confirms that, although gels are formed at lower temperature in the presence of ethanol, the mechanism of gelation and the structure of the network are not the same as in water. The effect of ethanol on Pluronic P123 was negligible. Similarly, cyclodextrin did not significantly alter the viscoelastic profiles at $37^{\circ} \mathrm{C}$ (Table 2 ).

3.2. $\beta L A P$ Solubilisation Capacity of the Pluronic Systems. The solubility of $\beta$ LAP in the Pluronic systems and the corresponding enhancement factor (EF) are shown in Table 3. Compared to water, Pluronic F127 formulations notably enhanced $\beta$ LAP solubility up to a copolymer concentration of $23 \%$; beyond that concentration a decrease was observed. General literature indicates that above CMC the solubility of a solute hosted in the micelles should increase linearly with the concentration of the surfactant [26]. The fact that $28 \%$ Pluronic solution does not solubilise the drug as well as $23 \%$ one does can be related to the relatively high viscosity of $28 \%$ Pluronic solutions even at $4^{\circ} \mathrm{C}$, which may make drug dissolution and diffusion difficult; the attainment of the equilibrium is delayed.

In agreement with the HLB values [12], Pluronic P123 (HLB 8) solubilised a higher amount of $\beta$ LAP than Pluronic F127 (HLB 22), although $\beta$ LAP solubility still remained below $1 \mathrm{mg} \cdot \mathrm{mL}^{-1}$. For such a poorly soluble drug, the single approach of micellization seems to be not enough to improve the aqueous solubility to the desirable extent [27], its combination with other solubilisation approaches being necessary. Both RM $\beta$ CD (5\% w/v) and ethanol $(20 \%$ $\mathrm{v} / \mathrm{v}$ ) (Table 3 ) enhanced $\beta$ LAP solubilisation to a great extent. RM $\beta C D$ increased the solubility in almost 50 -fold in both Pluronic F127 and P123, reaching drug concentrations close to $1.5 \mathrm{mg} \cdot \mathrm{mL}^{-1}$. Ethanol contributed even more to $\beta$ LAP solubilisation, particularly in P123 systems achieving a concentration of $2.4 \mathrm{mg} \cdot \mathrm{mL}^{-1}$.

3.3. In Vitro Release Assays. Drug release from an intratumoral implant is mainly controlled by diffusion, since the volume of fluid around the administration site is expected to be small and the dissolution of the polymer and the disintegration of the depot extremely slow [10, 11]. Pluronic systems containing $0.2 \mathrm{mg} \cdot \mathrm{mL}^{-1}$ drug concentration with adequate syringeability and gel temperature for intratumoral purposes were tested in regards to their drug release performance using diffusion cells. The selected membrane of 


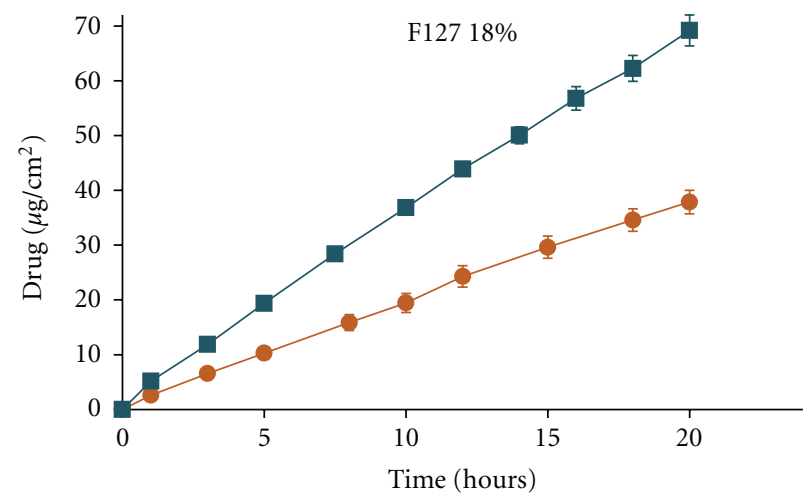

(a)

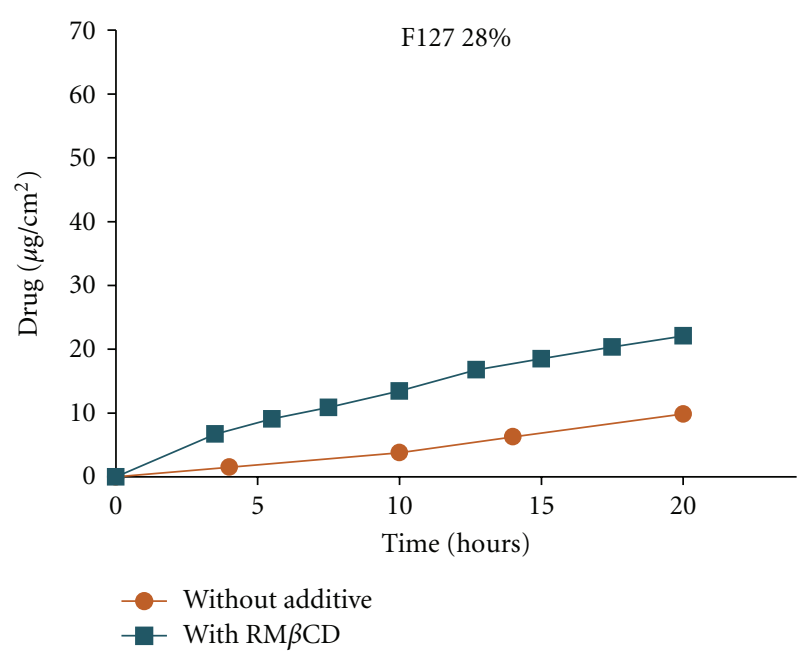

(c)

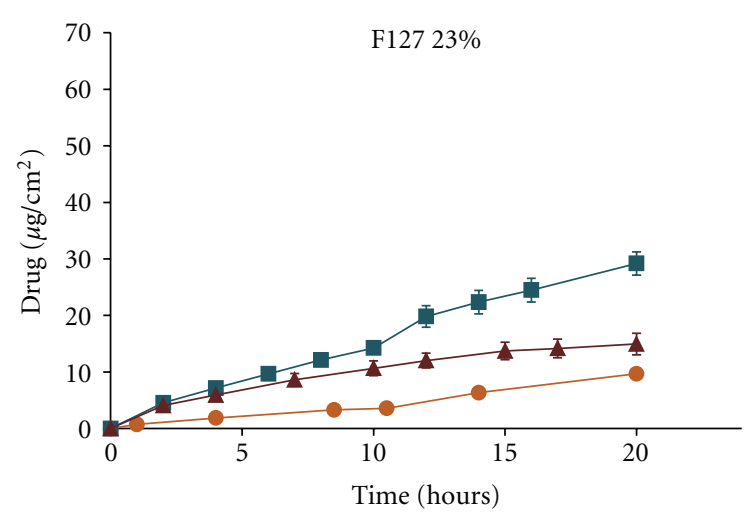

(b)

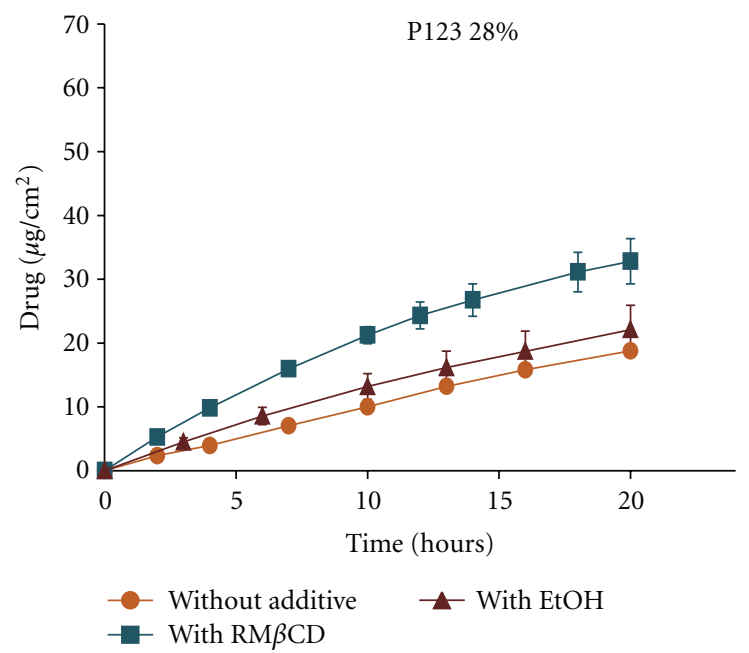

(d)

Figure 2: $\beta$ LAP release profiles of Pluronic F127 and P123 systems formulated with and without additives.

TABLE 3: $\beta$ LAP solubility $\left(\mathrm{mg} \cdot \mathrm{mL}^{-1}\right.$ ) and enhancement factor (EF) in F127 and in P123 systems at $4^{\circ} \mathrm{C}$ with and without $5 \%$ (w/v) $\mathrm{RM} \beta \mathrm{CD}$ and $20 \%(\mathrm{v} / \mathrm{v})$ ethanol: mean values and, in parenthesis, the standard deviations.

\begin{tabular}{|c|c|c|c|c|c|c|c|}
\hline & & \multicolumn{2}{|c|}{ Without additives } & \multicolumn{2}{|c|}{+ ethanol } & \multicolumn{2}{|c|}{$+\mathrm{RM} \beta \mathrm{CD}$} \\
\hline \multicolumn{2}{|c|}{ Pluronic \% } & {$[\beta \mathrm{LAP}]$} & $\mathrm{EF}$ & {$[\beta \mathrm{LAP}]$} & $\mathrm{EF}$ & {$[\beta \mathrm{LAP}]$} & $\mathrm{EF}$ \\
\hline \multirow{3}{*}{ F127 } & $18 \%$ & $0.248(0.032)$ & 8.3 & $0.660(0.051)$ & 22.0 & $1.037(0.141)$ & 34.6 \\
\hline & $23 \%$ & $0.444(0.108)$ & 14.8 & $1.183(0.102)$ & 34.4 & $1.487(0.117)$ & 49.6 \\
\hline & $28 \%$ & $0.208(0.028)$ & 7.0 & - & - & $0.767(0.141)$ & 25.6 \\
\hline P123 & $28 \%$ & $0.875(0.209)$ & 29.2 & $2.372(0.385)$ & 79.1 & $1.478(0.383)$ & 49.3 \\
\hline
\end{tabular}

7,000 Da cut-off enabled the movement of the drug towards the receptor compartment, the polymer being retained in the donor compartment.

As it has been previously described for other drugs, such as sodium diclofenac and quinine formulated in Pluronic gels $[28,29], \beta$ LAP release profiles fitted well to zero-order kinetics. Formulation including 23\% Pluronic F127 and 20\% ethanol is the one having the lowest correlation coefficient ( $r=0.967)$ but the model was maintained for comparison purposes (Table 4). In this formulation, the presence of ethanol spoils the gel structure of Pluronic F127 affecting its strength (Table 2 ) and consequently accelerating $\beta$ LAP release rate (Figure 2(b)). By contrast, ethanol does not seem to have any effect on drug release from Pluronic P123 formulation (Figure 2(d)) owing to the less disturbance of the rheological behaviour (Table 2).

A negative correlation was observed between Pluronic F127 concentration and the $\beta$ LAP release rate (Table 4). As the copolymer concentration raises, the entanglement of the copolymer chains also increases limiting drug diffusion [28]. Beyond certain copolymer concentration, the increase in macroviscosity does not correlate well with the hindrance to 
TABLE 4: Data from fitting $\beta$ LAP release profiles to zero-order kinetics and total amount of drug released at the end of the assay $\left(\mathrm{D}_{20}\right)$.

\begin{tabular}{|c|c|c|c|c|}
\hline Pluronic \% & Additive & Correlation coefficient & Slope $\left(\mu \mathrm{g} \mathrm{h} \cdot \mathrm{cm}^{-2}\right)$ & $\mathrm{D}_{20}\left(\mu \mathrm{g} \cdot \mathrm{cm}^{-2}\right)$ \\
\hline \multirow{2}{*}{ F127 18\% } & Without & 0.999 & 1.21 & 37.9 \\
\hline & $5 \%(\mathrm{w} / \mathrm{v}) \mathrm{RM} \beta \mathrm{CD}$ & 0.999 & 2.19 & 69.2 \\
\hline \multirow{3}{*}{ F127 23\% } & Without & 0.985 & 0.30 & 9.7 \\
\hline & $20 \%(\mathrm{v} / \mathrm{v}) \mathrm{EtOH}$ & 0.967 & 0.46 & 14.9 \\
\hline & $5 \%(\mathrm{w} / \mathrm{v}) \mathrm{RM} \beta \mathrm{CD}$ & 0.996 & 0.94 & 29.2 \\
\hline \multirow{2}{*}{ F127 28\% } & Without & 0.993 & 0.31 & 9.9 \\
\hline & $5 \%(\mathrm{w} / \mathrm{v}) \mathrm{RM} \beta \mathrm{CD}$ & 0.987 & 0.68 & 22.1 \\
\hline \multirow{3}{*}{ P123 28\% } & Without & 0.999 & 0.61 & 18.8 \\
\hline & $20 \%(\mathrm{v} / \mathrm{v}) \mathrm{EtOH}$ & 0.994 & 0.70 & 22.1 \\
\hline & $5 \%(\mathrm{w} / \mathrm{v}) \mathrm{RM} \beta \mathrm{CD}$ & 0.986 & 1.04 & 32.8 \\
\hline
\end{tabular}

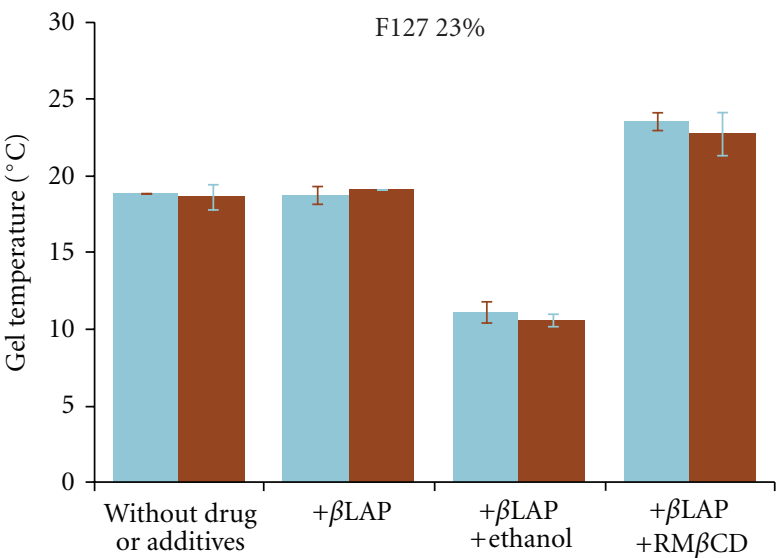

(a)

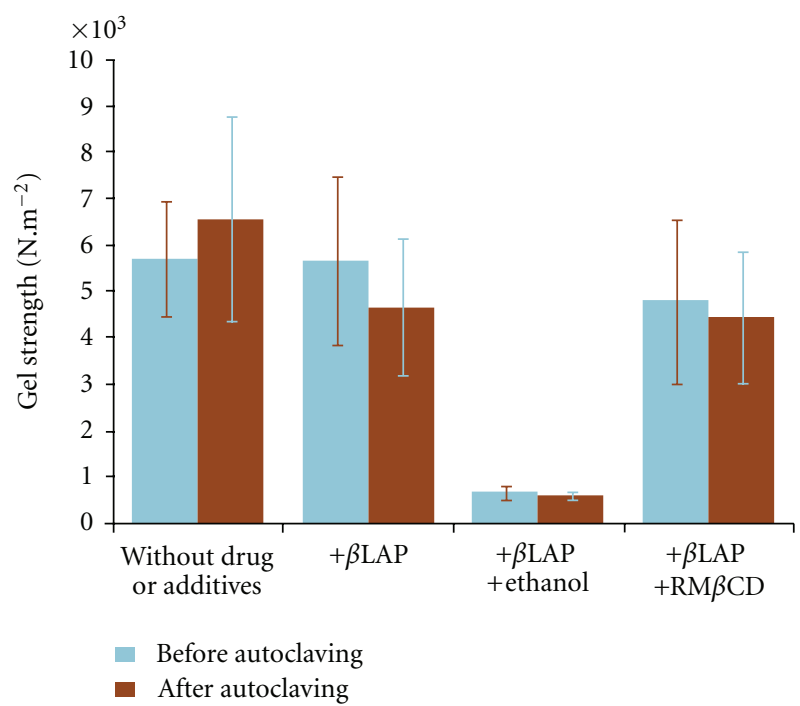

(c)

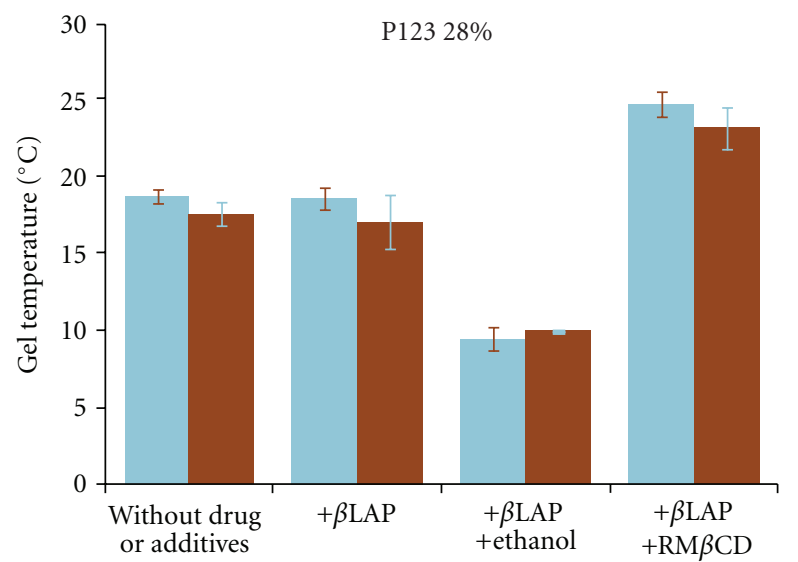

(b)

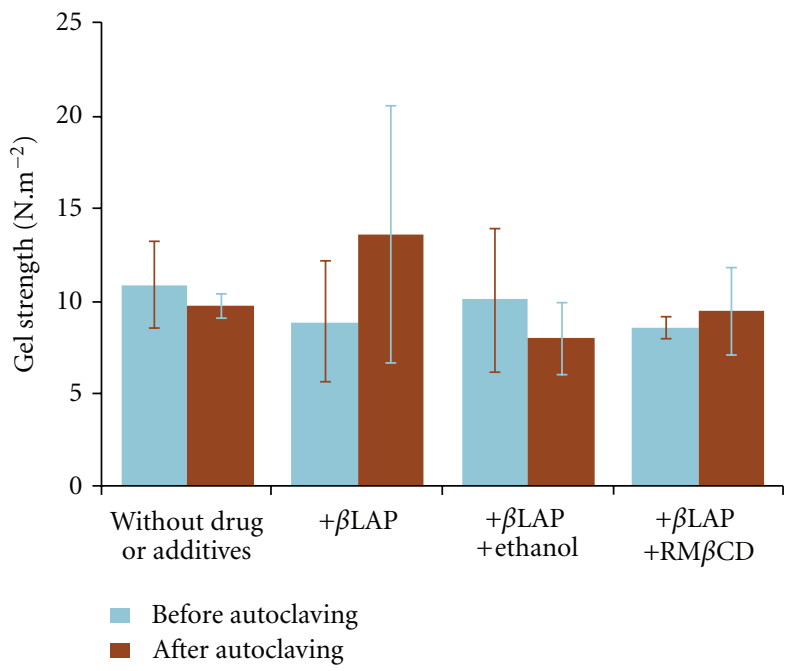

(d)

Figure 3: Gel temperature and gel strength at $37^{\circ} \mathrm{C}$ of Pluronic systems before and after autoclaving. 
diffusion and similar release profiles can be obtained [30]. This justifies the similar release kinetics observed for $23 \%$ and 28\% Pluronic F127 systems. Changes in the release rate of $\beta$ LAP from Pluronic systems containing ethanol could be explained by the reduction in the gel strength of the formulations together with the increment in drug solubility.

Although RM $\beta C D$ did not alter the gel strength profiles of the Pluronic dispersions (Table 2), it greatly accelerated drug release (Figure 2). This effect can be explained by the increase in $\beta$ LAP solubility as a consequence of complex formation with $\mathrm{RM} \beta \mathrm{CD}$ [8]. The mesh size network of the Pluronic gels seems to be great enough to allow the diffusion of the drug-RM $\beta \mathrm{CD}$ complexes.

3.4. Autoclaving. No statistically significant differences were denoted in the gel temperature or gel strength of the samples before and after autoclaving (Figure 3) which is in agreement with the physical stability of the Pluronic dispersions pointed out by different authors [16, 31]. No crystalline growth was observed under optical microscopy. Samples show that the same UV-visible spectra and $\beta$ LAP amount before and after autoclaving are not significantly different [32]. Therefore, autoclaving could be recommended as a sterilization method for these intratumoral formulations.

\section{Conclusions}

Pluronic P123 systems have a high capacity of $\beta$ LAP incorporation, especially when ethanol $(20 \%)$ is present in the formulation. However, the low gel strength of those systems does not guarantee the permanence of the formulation in the application site for a long period of time. Pluronic F127 in the $18-23 \%$ range presents better perspectives for intratumoral formulation development. It combines adequate gel temperature range $\left(20-30^{\circ} \mathrm{C}\right)$ and the gel strength at $37^{\circ} \mathrm{C}$ may be enough to delay erosion and to control drug release rate. The $\beta$ LAP loading and the release rate can be tuned by the copolymer concentration and the addition of RM $\beta C D$. The use of ethanol in combination with Pluronic F127 should be avoided as this cosolvent led to soft gels at $37^{\circ} \mathrm{C}$. Autoclaving does not affect the physical-chemical properties of the Pluronic systems and may be a suitable sterilization method for the intratumoral formulations. Thus, $\beta \mathrm{LAP}$ formulated in temperature-sensitive Pluronic gels may have good perspectives for intratumoral delivery purposes.

\section{Conflict of Interests}

The authors declare that they have no conflict of interests.

\section{Acknowledgments}

The authors thank LAFEPE, Brazil, and Professor Dr. Pedro Jose Rolim Neto, Federal University of Pernambuco, Brazil, for their kind gift of the $\beta$ LAP and Ms. J. Menis for her help in the correction of the English version of the work. This work was supported by Xunta de Galicia (Grant no. PGIDIT008CSA007203PR) and the Programme Al $\beta$ an, the
European Union Programme of High Level Scholarships for Latin America (scholarship number E04D043994BR). M. Landin thanks the Spanish MEC for her financial support (PR2010-0460) during her sabbatical at the Faculty of Science, University of Utrecht (The Netherlands).

\section{References}

[1] J. K. Jackson, X. Zhang, S. Llewellen, W. L. Hunter, and H. M. Burt, "The characterization of novel polymeric paste formulations for intratumoral delivery," International Journal of Pharmaceutics, vol. 270, no. 1-2, pp. 185-198, 2004.

[2] N. Mirahmadi, M. H. Babaei, A. M. Vali, and S. Dadashzadeh, "Effect of liposome size on peritoneal retention and organ distribution after intraperitoneal injection in mice," International Journal of Pharmaceutics, vol. 383, no. 1-2, pp. 7-13, 2010.

[3] J. J. Pink, S. M. Planchon, C. Tagliarino, M. E. Varnes, D. Siegel, and D. A. Boothman, "NAD $(\mathrm{P}) \mathrm{H}$ : quinone oxidoreductase activity is the principal determinant of $\beta$-lapachone cytotoxicity," Journal of Biological Chemistry, vol. 275, no. 8, pp. 5416-5424, 2000.

[4] A. B. Pardee, Y. Z. Li, and C. J. Li, "Cancer therapy with $\beta$ lapachone," Current Cancer Drug Targets, vol. 2, no. 3, pp. 227242, 2002.

[5] Y. Li, X. Sun, J. T. LaMont, A. B. Pardee, and C. J. Li, "Selective killing of cancer cells by $\beta$-lapachone: direct checkpoint activation as a strategy against cancer," Proceedings of the National Academy of Sciences of the United States of America, vol. 100, no. 5, pp. 2674-2678, 2003.

[6] A. D'Anneo, G. Augello, A. Santulli et al., "Paclitaxel and beta-lapachone synergistically induce apoptosis in human retinoblastoma Y79 cells by downregulating the levels of phospho-Akt," Journal of Cellular Physiology, vol. 222, no. 2, pp. 433-443, 2010.

[7] N. Nasongkla, A. F. Wiedmann, A. Bruening et al., "Enhancement of solubility and bioavailability of beta-lapachone using cyclodextrin inclusion complexes," Pharmaceutical Research, vol. 20, no. 10, pp. 1626-1633, 2003.

[8] M. S. S. Cunha-Filho, B. Dacunha-Marinho, J. J. TorresLabandeira, R. Martínez-Pancheco, and M. Landín, "Characterization of $\beta$-lapachone and methylated $\beta$-cyclodextrin solid-state systems," AAPS PharmSciTech, vol. 8, no. 3, article no. 60, 2007.

[9] M. Ough, A. Lewis, E. A. Bey et al., "Efficacy of $\beta$-lapachone in pancreatic cancer treatment: exploiting the novel, therapeutic target NQO1," Cancer Biology and Therapy, vol. 4, no. 1, pp. 95-102, 2005.

[10] M. M. Amiji, P. K. Lai, D. B. Shenoy, and M. Rao, "Intratumoral administration of paclitaxel in an in situ gelling poloxamer 407 formulation," Pharmaceutical Development and Technology, vol. 7, no. 2, pp. 195-202, 2002.

[11] T. Arai, T. Joki, M. Akiyama et al., "Novel drug delivery system using thermoreversible gelation polymer for malignant glioma," Journal of Neuro-Oncology, vol. 77, no. 1, pp. 9-15, 2006.

[12] A. V. Kabanov, E. V. Batrakova, and V. Y. Alakhov, "Pluronic block copolymers as novel polymer therapeutics for drug and gene delivery," Journal of Controlled Release, vol. 82, no. 2-3, pp. 189-212, 2002.

[13] S. R. Croy and G. S. Kwon, "Polymeric micelles for drug delivery," Current Pharmaceutical Design, vol. 12, no. 36, pp. 4669-4684, 2006. 
[14] M. Yokoyama, "Polymeric micelles as a new drug carrier system and their required considerations for clinical trials," Expert Opinion on Drug Delivery, vol. 7, no. 2, pp. 145-158, 2010.

[15] V. L. Glen, P. R. Hutson, N. J. Kehrli, D. A. Boothman, and G. Wilding, "Quantitation of $\beta$-lapachone and 3-hydroxy- $\beta$ lapachone in human plasma samples by reversed-phase highperformance liquid chromatography," Journal of Chromatography B, vol. 692, no. 1, pp. 181-186, 1997.

[16] G. Dumortier, N. E. Kateb, M. Sahli, S. Kedjar, A. Boulliat, and J. C. Chaumeil, "Development of a thermogelling ophthalmic formulation of cysteine," Drug Development and Industrial Pharmacy, vol. 32, no. 1, pp. 63-72, 2006.

[17] V. Y. Alakhov, E. Y. Moskaleva, E. V. Batrakova, and A. V. Kabanov, "Hypersensitization of multidrug resistant human ovarian carcinoma cells by pluronic P85 block copolymer," Bioconjugate Chemistry, vol. 7, no. 2, pp. 209-216, 1996.

[18] D. Y. Alakhova, N. Y. Rapoport, E. V. Batrakova et al., "Differential metabolic responses to pluronic in MDR and non-MDR cells: a novel pathway for chemosensitization of drug resistant cancers," Journal of Controlled Release, vol. 142, no. 1, pp. 89$100,2010$.

[19] G. Dumortier, J. L. Grossiord, F. Agnely, and J. C. Chaumeil, "A review of poloxamer 407 pharmaceutical and pharmacological characteristics," Pharmaceutical Research, vol. 23, no. 12, pp. 2709-2728, 2006.

[20] D. S. Jones, A. F. Brown, and A. D. Woolfson, "Solute and solvent effects on the thermorheological properties of poly(oxyethylene)-poly(oxypropylene) block copolymers: implications for pharmaceutical dosage form design," Journal of Applied Polymer Science, vol. 87, no. 6, pp. 1016-1026, 2003.

[21] C. Chaibundit, N. M. P. S. Ricardo, C. A. Muryn, M. B. Madec, S. G. Yeates, and C. Booth, "Effect of ethanol on the gelation of aqueous solutions of Pluronic F127," Journal of Colloid and Interface Science, vol. 351, no. 1, pp. 190-196, 2010.

[22] L. Nogueiras-Nieto, C. Alvarez-Lorenzo, I. Sandez-Macho, A. Concheiro, and F. J. Otero-Espinar, "Hydrosoluble cyclodextrin/poloxamer polypseudorotaxanes at the air/water interface, in bulk solution, and in the gel state," Journal of Physical Chemistry B, vol. 113, no. 9, pp. 2773-2782, 2009.

[23] K. Newell, A. Franchi, J. Pouysségur, and I. Tannock, "Studies with glycolysis-deficient cells suggest that production of lactic acid is not the only cause of tumor acidity," Proceedings of the National Academy of Sciences of the United States of America, vol. 90, no. 3, pp. 1127-1131, 1993.

[24] B. Bharatiya, C. Guo, J. H. Ma, P. A. Hassan, and P. Bahadur, "Aggregation and clouding behavior of aqueous solution of EO-PO block copolymer in presence of n-alkanols," European Polymer Journal, vol. 43, no. 5, pp. 1883-1891, 2007.

[25] E. Kim, Z. Gao, J. Park, H. Li, and K. Han, "rhEGF/HP$\beta$-CD complex in poloxamer gel for ophthalmic delivery," International Journal of Pharmaceutics, vol. 233, no. 1-2, pp. 159-167, 2002.

[26] C. O. Rangel-Yagui, A. Pessoa Jr., and L. Costa Tavares, "Micellar solubilization of drugs," Journal of Pharmacy and Pharmaceutical Sciences, vol. 8, no. 2, pp. 147-163, 2005.

[27] V. Rao, M. Nerurkar, S. Pinnamaneni, F. Rinaldi, and K. Raghavan, "Co-solubilization of poorly soluble drugs by micellization and complexation," International Journal of Pharmaceutics, vol. 319, no. 1-2, pp. 98-106, 2006.

[28] Y. J. Park, C. S. Yong, H. M. Kim et al., "Effect of sodium chloride on the release, absorption and safety of diclofenac sodium delivered by poloxamer gel," International Journal of Pharmaceutics, vol. 263, no. 1-2, pp. 105-111, 2003.

[29] F. Fawaz, A. Koffi, M. Guyot, and P. Millet, "Comparative in vitro-in vivo study of two quinine rectal gel formulations," International Journal of Pharmaceutics, vol. 280, no. 1-2, pp. 151-162, 2004.

[30] C. Alvarez-Lorenzo, J. L. Gomez-Amoza, R. MartínezPacheco, C. Souto, and A. Concheiro, "Microviscosity of hydroxypropylcellulose gels as a basis for prediction of drug diffusion rates," International Journal of Pharmaceutics, vol. 180, no. 1, pp. 91-105, 1999.

[31] R. Cavalli, O. Caputo, M. E. Carlotti, M. Trotta, C. Scarnecchia, and M. R. Gasco, "Sterilization and freeze-drying of drug-free and drug-loaded solid lipid nanoparticles," International Journal of Pharmaceutics, vol. 148, no. 1, pp. 47-54, 1997.

[32] M. S. S. Cunha-Filho, A. Estévez-Braun, E. Pérez-Sacau et al., "Light effect on the stability of $\beta$-lapachone in solution: pathways and kinetics of degradation," Journal of Pharmacy and Pharmacology, vol. 63, pp. 1156-1160, 2011. 

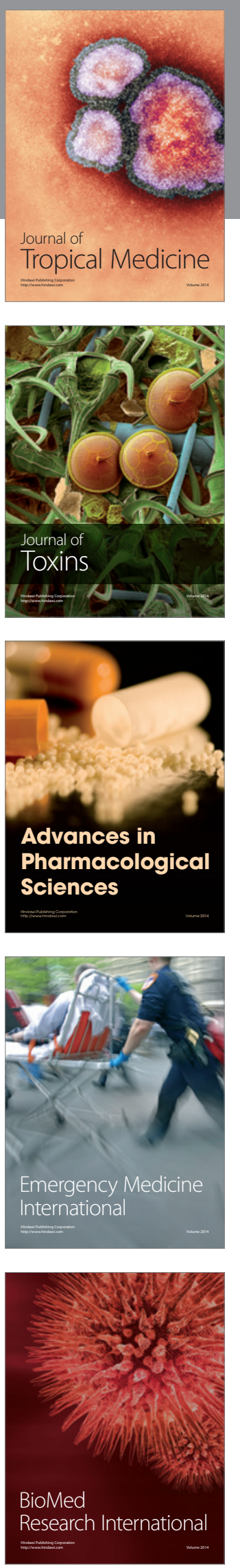
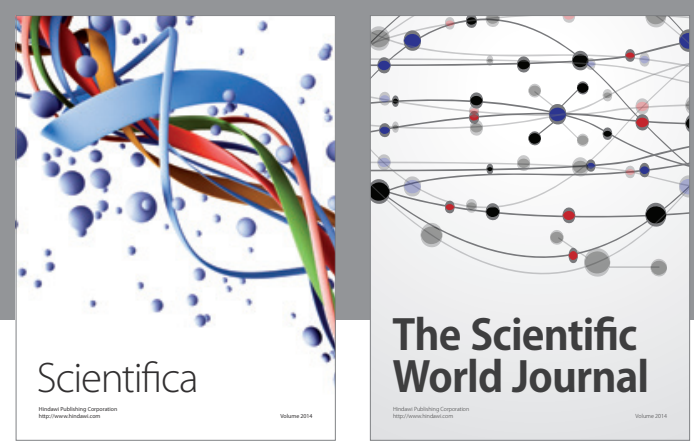

The Scientific World Journal
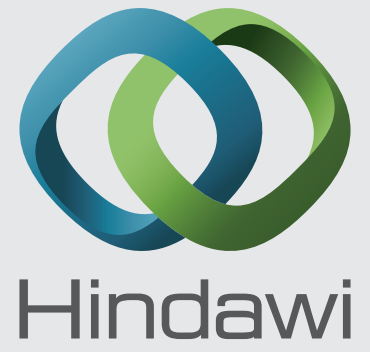

Submit your manuscripts at

http://www.hindawi.com
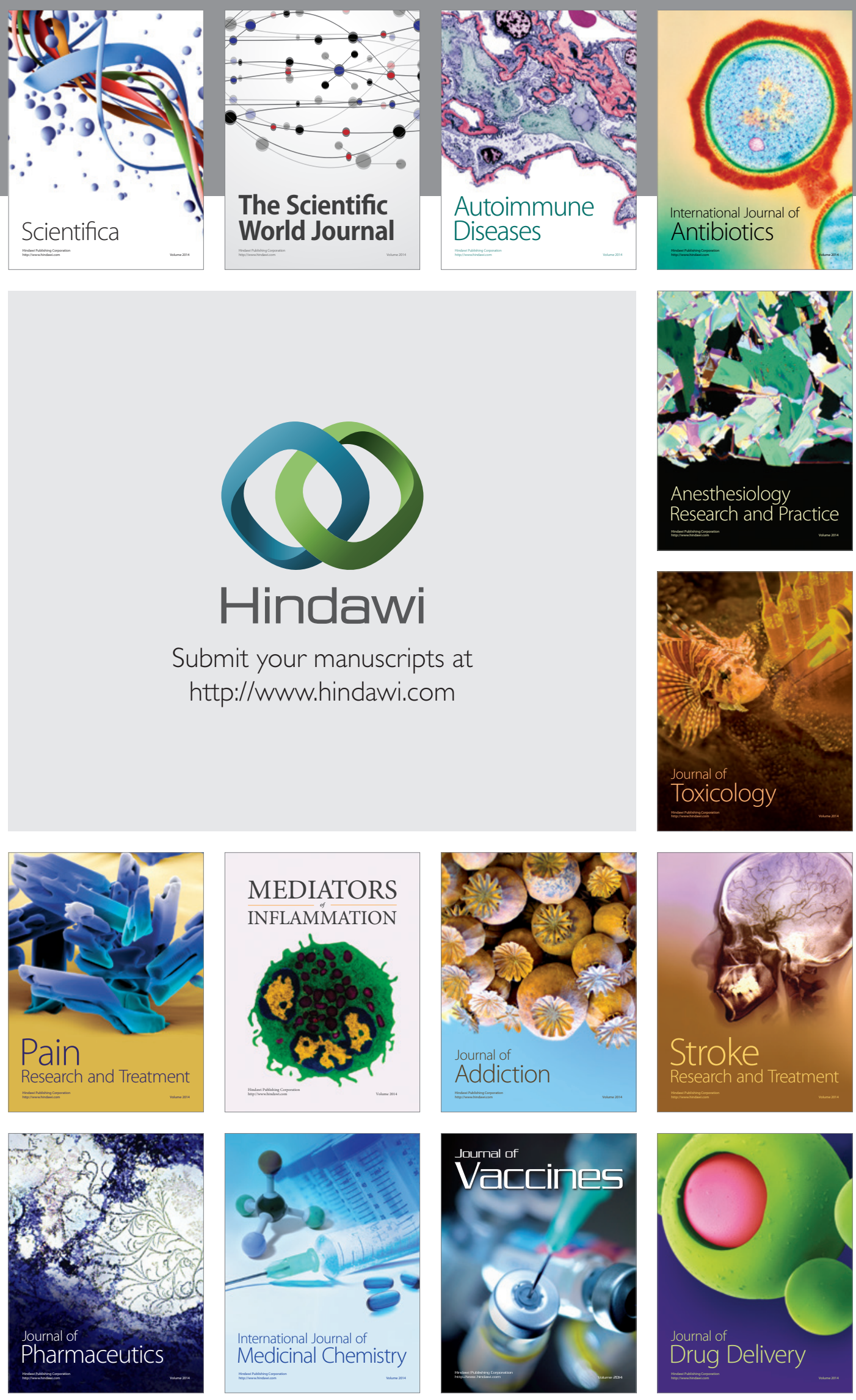